extraluminal vein stripper preserves endothelium in a similar fashion as conventional vein harvest. This, coupled with the established superiority of the Mayo stripper in reducing postoperative leg wound infections, the short learning curve, and no additional financial implications, makes the use of this underused surgical aid from the past a very attractive option, even in the modern era.

\footnotetext{
References

1. Dimitri WR, West IE, Williams BT. A quick and atraumatic method of autologous vein harvesting using the subcutaneous extraluminal dissector. J Cardiovasc Surg (Torino). 1987;28:103-11.

2. O'Regan J, Borland JAA, Chester AH, Pennell DJ, Yacoub M, Pepper JR. Assessment of human long saphenous vein function with minimally invasive harvesting with the Mayo stripper. Eur J Cardiothorac Surg. 1997;12:428-35.

3. Bryan AJ, Angelini GD. The biology of saphenous vein graft occlusion: etiology and strategies for prevention. Curr Opin Cardiol. 1994;9:641-9.
}

4. Logerfo FW, Quist WC, Cantelmo NL, Haudenschild CC. Integrity of vein grafts as a function of initial intimal and medial preservation. Circulation. 1983;68:117-24.

5. Shuhaiber JH, Evans AN, Masssad MG, Geha AS. Mechanisms and future directions for prevention of vein graft failure in coronary bypass surgery. Eur J Cardiothorac Surg. 2002;22:387-96.

6. Zilla P, Von Oppell U, Deutsch M. The endothelium: a key to the future. J Card Surg. 1993;8:32-60.

7. Cataldo G, Braga M, Pirotta N, Lavezzari M, Rovelli F, Marubini E. Factors influencing 1 year patency of coronary artery saphenous vein grafts. Studio Indobufene nel Bypass Aortocoronarico (SINBA). Circulation. 1993;88:II93-8.

8. Paz MA, Lupon J, Bosch X, Pomar JL, Sanz G. Predictors of early saphenous vein aortocoronary bypass graft occlusion. The GESIC Study Group. Ann Thorac Surg. 1993;56:1101-6.

9. Isgro F, Weisse U, Voss B, Kiessling AH, Saggau W. Minimally invasive saphenous vein harvesting: is there an improvement of the results with the endoscopic approach? Eur J Cardiothorac Surg. 1999;16(suppl):S58-60.

10. Carpino PA, Khabbaz KR, Bojar RM, Rastegar H, Warner KG, Murphy RE, et al. Clinical benefits of endoscopic vein harvesting in patients with risk factors for saphenectomy wound infections undergoing coronary artery bypass grafting. J Thorac Cardiovasc Surg. 2000;119:69-76.

\title{
Minimally invasive transaortic thoracoscopic resection of an apical left ventricular myxoma
}

\author{
Paul Modi, FRCS, Ansar Hassan, MD, PhD, and W. Randolph Chitwood, Jr, MD, Greenville, NC
}

Minimally invasive cardiac valvular surgery is associated with decreased pain, reduced blood loss, faster recovery, superior cosmetic results, and greater patient satisfaction when compared with sternotomy approaches. Despite this, these techniques have rarely been used for intracardiac tumor resections, which have traditionally been performed through a median sternotomy. Tumors situated in the left ventricular apex represent a surgical challenge because it is a difficult area to access without a left ventriculotomy and its attendant complications. A recent report in the Journal describes the use of a thoracoscopic transaortic approach to resect a left ventricular fibroelastoma through a median sternotomy. ${ }^{1}$ To combine a thoracoscopic instrument with a median sternotomy seems paradoxical, and therefore we describe a truly minimally invasive approach to an apical left ventricular myxoma that we have used involving a thoracoscopic approach combined with a right anterior minithoracotomy.

\footnotetext{
From the East Carolina Heart Institute, East Carolina University, Greenville, NC. Received for publication March 21, 2008; accepted for publication April 13, 2008 Address for reprints: W. Randolph Chitwood, Jr, MD, East Carolina Heart Institute, East Carolina University, Pitt County Memorial Hospital, 600 Moye Blvd, Greenville, NC, 27834 (E-mail: chitwoodw@ecu.edu).

J Thorac Cardiovasc Surg 2009;138:510-12

0022-5223/\$36.00

Copyright (c) 2009 by The American Association for Thoracic Surgery doi:10.1016/j.jtcvs.2008.04.025
}

\section{CLINICAL SUMMARY}

A 65-year-old asymptomatic man, while undergoing echocardiographic work-up for a cardiac murmur, was discovered to have a $12-\mathrm{mm} \times 9-\mathrm{mm}$ tumor at the junction of the mid and apical lateral segments of the left ventricle (Figure 1, A). There was no significant valvular disease nor was there any history of thromboembolic events. There was no significant coronary disease. He was referred for surgical excision, which was accomplished with a minimally invasive technique.

A left-sided, double-lumen endotracheal tube and a 17F right internal jugular-superior vena cava Bio-medicus cannula (Medtronic, Inc, Minneapolis, Minn) were positioned. The right chest was elevated $20^{\circ}$, and a $5-\mathrm{cm}$ right anterior (second intercostal space) minithoracotomy was made just lateral to the right internal thoracic artery. A soft tissue retractor (Cardiovations; Edwards Lifesciences, Irvine, Calif) was deployed, and a pericardial well was created. A 5-mm videoscope port was positioned lateral to the incision, and a voiceactivated robotic arm was used for camera manipulation (AESOP 3000; Computer Motion, Inc, Galeta, Ca). The operative field was flooded with carbon dioxide $(4 \mathrm{~L} / \mathrm{min})$.

The femoral vessels were cannulated through a $2-\mathrm{cm}$ groin incision with the Seldinger guidewire-transesophageal echocardiographic visualization method (arterial: 17F-19F cannula, venous: 22F-25F long multistage cannula). After commencing vacuum-assisted cardiopulmonary bypass, 

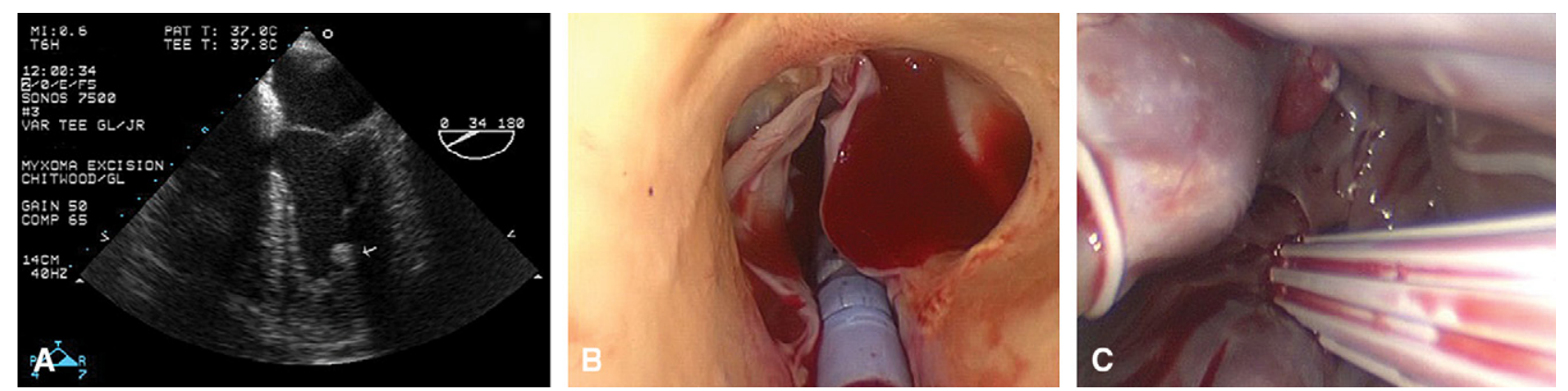

FIGURE 1. A, Transesophageal echocardiogram showing a left ventricular myxoma (arrow). B, Operative view of the aortic valve before manipulating the thoracoscope across it. C, Videoscopic view of the left ventricular myxoma.

the systemic temperature was decreased to $28^{\circ} \mathrm{C}$, a transthoracic aortic clamp was deployed (Scanlan, Saint Paul, Minn), and aortic root cardioplegia was administered. A longitudinal aortotomy was performed, the aortic valve was gently retracted, and a left ventricular vent was inserted under direct vision (Figure 1, B). The thoracoscope was then gently manipulated into the left ventricular cavity to provide optimal visualization of the tumor (Figure 1,C). This easily enabled complete resection of the mass with standard long-shafted instruments. Finally, the aortic valve was inspected for competency, the aortotomy was closed, the heart was deaired, the aortic clamp was removed, and the patient was weaned from cardiopulmonary bypass after 66 minutes. Postoperative echocardiographic analysis demonstrated no residual tumor. The patient had an uneventful recovery, was discharged on the fourth postoperative day, and was back to normal activity by 4 weeks. Histologic examination confirmed myxoma. The cosmetic result 8 weeks after the operation is shown in Figure 2.

\section{DISCUSSION}

Ventricular myxomas are extremely rare and account for $3 \%$ to $5 \%$ of all myxomas. They typically arise from the free wall of the right ventricle, whereas those arising from the left ventricle originate near the posterior papillary muscle, inferior wall, or interventricular septum. Prompt surgical excision is indicated to prevent either embolic complications or intracardiac obstruction. Tumors arising from the left ventricular inflow tract have been approached through the mitral valve, occasionally with detachment of the anterior leaflet to aid exposure, ${ }^{2}$ whereas tumors in the left ventricular outflow tract can be removed with a transaortic approach. Videoscopic assistance can be used in either of these circumstances to enhance visualization and lighting in the deeper periapical segments of the left ventricle. A ventriculotomy should only be performed when other techniques prove inadequate because of the attendant risks of arrhythmia, aneurysm, or impairment of left ventricular function.

There are no prior reports of a minimally invasive approach to left ventricular tumors. However, these techniques have been applied to atrial tumors (hemisternotomy or fourth interspace minithoracotomy) with videoscopic or robotic assistance and to aortic valve tumors (hemisternotomy). ${ }^{3,4}$ A right anterior minithoracotomy has been described for aortic valve replacement and has been shown to allow earlier extubation and promote shorter intensive care unit and hospital stays compared with conventional sternotomy. ${ }^{5}$ It would be reasonable to expect similar benefits for cardiac tumor excision.

In conclusion, minimally invasive endoscopic resection of left ventricular tumors is feasible, safe, and associated with a rapid recovery. Larger series with this technique are

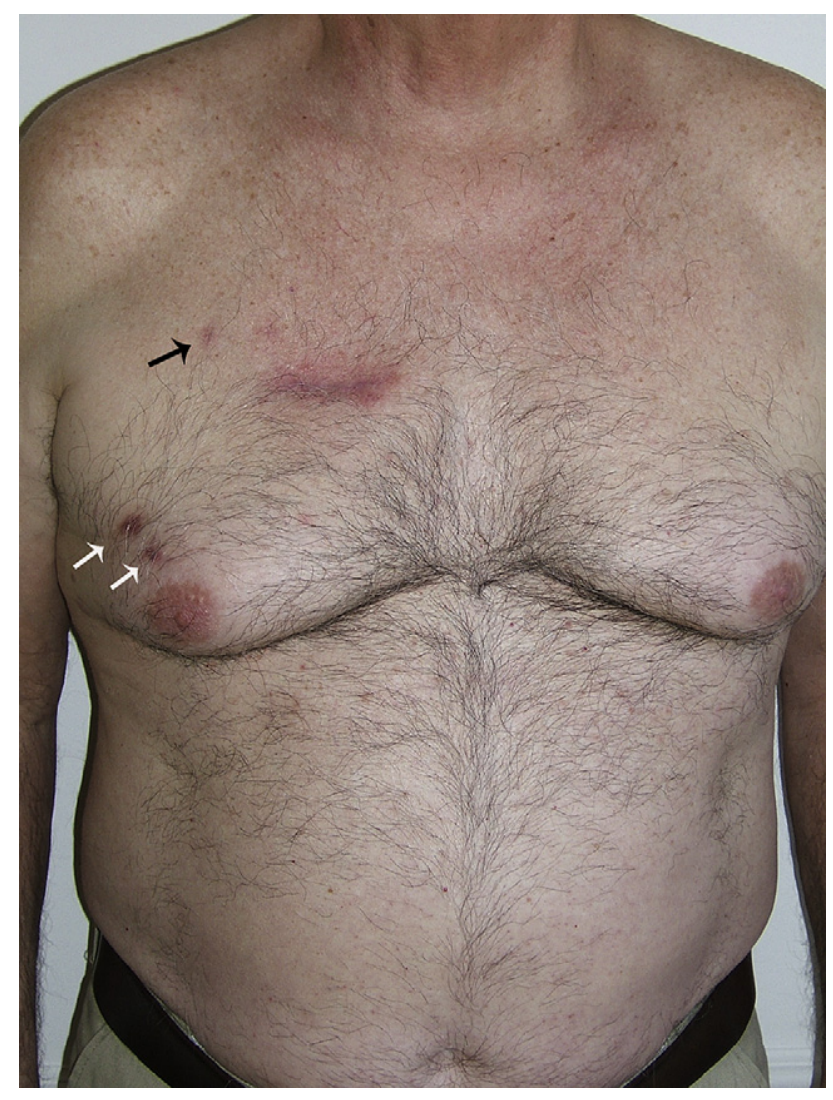

FIGURE 2. Cosmetic result 8 weeks postoperatively. Black arrow, Site of videoscope insertion; white arrows, chest tube sites. 
necessary to establish this approach, and thus this method deserves further clinical evaluation.

\section{References}

1. Walkes JC, Bavare C, Blackmon S, Reardon MJ. Transaortic resection of an apical left ventricular fibroelastoma facilitated by a thoracoscope. $J$ Thorac Cardiovasc Surg. 2007;134:793-4.
2. Talwalkar NG, Livesay JJ, Treistman B, Lacle CE. Mobilization of the anterior mitral leaflet for excision of a left ventricular myxoma. Ann Thorac Surg. 1999; 67:1476-8.

3. Grande AM, Massetti M, Castiglione N, Vigano M. Valve-sparing removal of aortic fibroelastoma through ministernotomy. J Heart Valve Dis. 2007;16:206-8.

4. Murphy DA, Miller JS, Langford DA. Robot-assisted endoscopic excision of left atrial myxomas. J Thorac Cardiovasc Surg. 2005;130:596-7.

5. Wheatley GH 3rd, Prince SL, Herbert MA, Ryan WH. Port-access aortic valve surgery: a technique in evolution. Heart Surg Forum. 2004;7:E628-31. 